\title{
LIQUEFACTION ASSESSMENT OF RECLAIMED LAND AT CENTREPORT, WELLINGTON
}

\author{
Riwaj Dhakal ${ }^{1}$, Misko Cubrinovski ${ }^{2}$, Jonathan D. Bray ${ }^{3}$ and \\ Christopher de la Torre ${ }^{4}$
}

(Submitted October 2019; Reviewed November 2019; Accepted December 2019)

\begin{abstract}
Observations of liquefaction-induced damage at the port of Wellington (CentrePort) provide an opportunity to evaluate the applicability of state-of-the-practice liquefaction evaluation methodologies on reclaimed land. This study focuses on the application of widely used simplified liquefaction assessment methods on the enddumped gravelly fills and hydraulically-placed silty and sandy fills at CentrePort for the 2013 Cook Strait, 2013 Lake Grassmere, and 2016 Kaikōura earthquakes. Liquefaction assessment of the gravel reclamation poses several challenges due to its large percentage of gravel-sized particles making it difficult to obtain highquality in situ data. The hydraulic fills at CentrePort are also of significant interest as they relate to a range of issues in the simplified engineering assessment around effects of fines and their plasticity on the liquefaction resistance. Following the 2016 Kaikoura earthquake, subsurface explorations were performed which included 121 Cone Penetration Tests (CPTs). Results of CPT-based liquefaction triggering and postliquefaction reconsolidation settlement assessments using state-of-the-practice procedures are discussed and compared with observed liquefaction manifestation and settlements.
\end{abstract}

\section{INTRODUCTION}

Recent earthquakes in New Zealand have produced major damage due to soil liquefaction. In the 2010-2011 Canterbury earthquakes, widespread and damaging liquefaction occurred in native fluvial soil in Christchurch. In the 2016 Kaikoura Earthquake, reclaimed land liquefied causing substantial damage to port structures and loss of operations. While it is not surprising that saturated, loose fluvial sandy soils and uncompacted reclaimed fills liquefied during these earthquakes, there are several issues in the conventional engineering evaluation of liquefaction that require further scrutiny. For example, liquefaction of gravelly soils, which are commonly found in reclaimed land at ports, requires further attention. Currently, triggering and consequences of liquefaction are evaluated using semi-empirical methods based on field case histories with databases predominantly on clean sand and nonplastic silty sand deposits. There are few case histories involving reclaimed soil composed of a wide range of grain sizes including gravel. Thus, it is necessary to scrutinise and, if necessary, modify current simplified methods when applying them to non-standard soil such as the gravels found at the port of Wellington (CentrePort).

The hydraulic fills at CentrePort are also of significant interest as they relate to a range of issues in the simplified engineering assessment around effects of fines and their plasticity on the liquefaction resistance. During the Kaikoura earthquake, one part of the hydraulic fills at CentrePort liquefied severely, however, most of these fills did not manifest liquefaction. There was a clear contrast in the seismic performance of the hydraulic fills. Hence, there is wealth of scientific and practical engineering information in the observed performance of CentrePort fills that is of great significance and can improve our understanding and evaluation of liquefaction and its effects on reclaimed land.
This paper presents and discusses results from comprehensive Cone Penetration Test (CPT) field investigations for geotechnical characterisation of the fills at CentrePort, and then uses the CPT data to perform simplified liquefaction triggering analyses, and then estimate post-liquefaction settlement and consequent damage. Three recent earthquakes were considered in the assessment to investigate the performance of the fills and simplified methods of analysis for different levels of intensity of ground motions. Key findings from the characterisation of the reclamations and liquefaction analyses are discussed including comparisons of the estimated ground settlement with the observed ground settlement.

\section{SITE DESCRIPTION}

Wellington, the capital city of New Zealand, is located near the southern tip of the North Island as depicted in Figure 1. The city was developed over the past 170 years after the European settlement in the 1850's [1]. The original coastline from the 1850 's is approximately $200 \mathrm{~m}$ to $500 \mathrm{~m}$ inland from the current revetment line delineating a belt of reclaimed land that increases in width towards the north along the waterfront and reaches its largest extent at CentrePort.

The reclaimed land in the Wellington waterfront area comprises soils of different age, method of construction and thickness. The reclamations were constructed over three periods (Figure 2). Fills were initially constructed from the late 1880's to 1916 . Most of the hydraulic fills were constructed from 1924 to 1932 , whereas a large portion of the current port area, i.e. the Thorndon reclamation, was reclaimed in the final phase of construction between 1965 and 1976. This most recent reclamation is separated from the rest of the reclaimed land by an old buried concrete seawall, a remnant bulkhead, depicted in Figure 2. This figure shows an aerial view of CentrePort highlighting details of construction periods, soil used for the reclamation, and strong motion stations at CentrePort.

\footnotetext{
1 Corresponding Author, PhD Student, Department of Civil and Natural Resources Engineering, University of Canterbury, NZ ribu.dhakal@pg.canterbury.ac.nz

2 Professor, Department of Civil and Natural Resources Engineering, University of Canterbury, NZ misko.cubrinovski@ canterbury.ac.nz (Member)

3 Professor, Department of Civil and Environmental Engineering, University of California, Berkeley, CA, USA jonbray@berkeley.edu

${ }^{4}$ PhD Student, Department of Civil and Natural Resources Engineering, University of Canterbury, NZ christopher.delatorre@pg.canterbury.ac.nz
} 


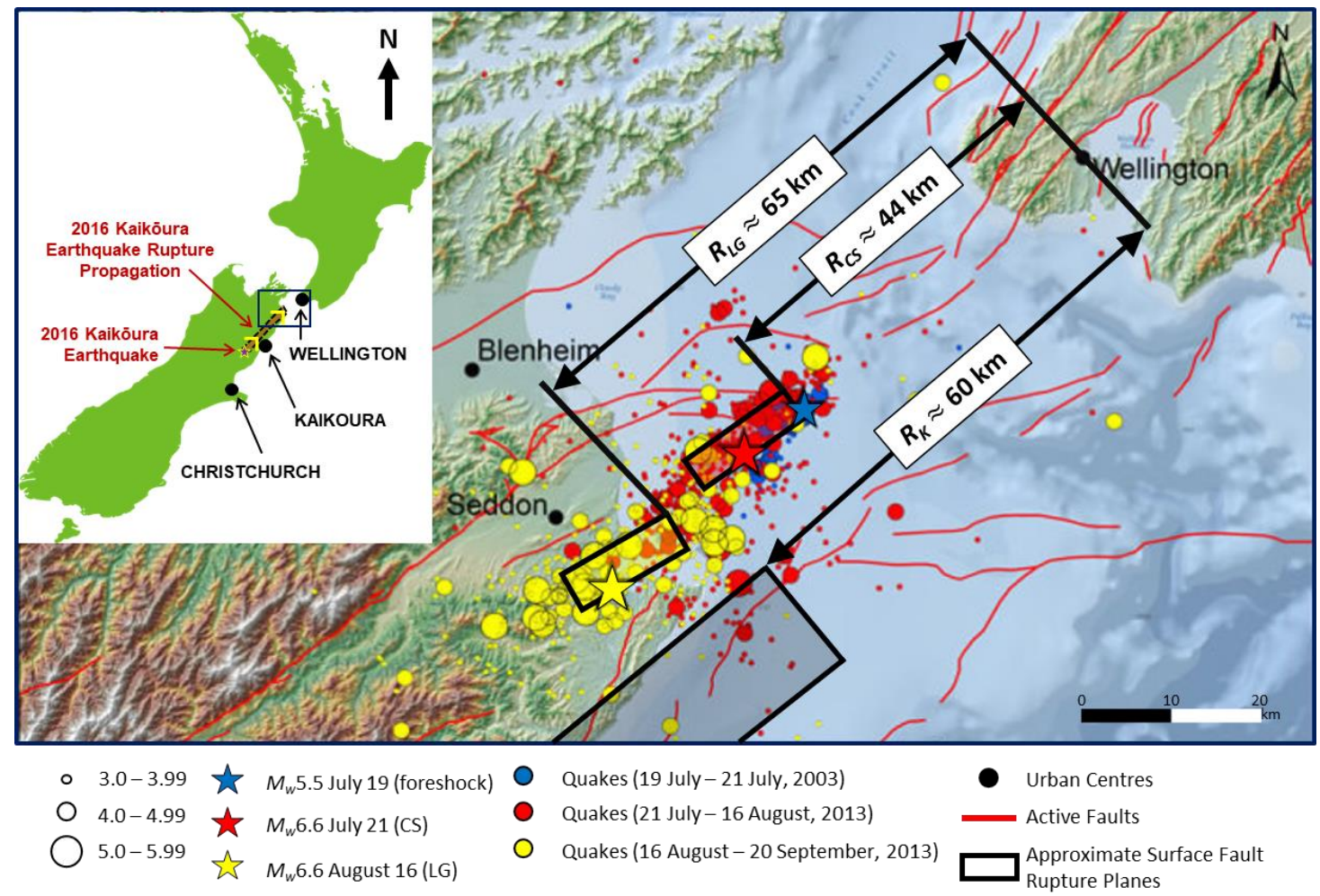

Figure 1: Map of approximate surface fault rupture planes of the 2016 Kaikōura, 2013 Cook Strait, and 2013 Lake Grassmere earthquakes with respective source-to-site distances $\left(R_{R U P}\right)$ denoted as $R_{K}, R_{C S}$ and $R_{L G}$. The inset indicates the source zone and direction of rupture propagation for the 2016 Kaikoura earthquake. The seismic activity for the 2013 earthquakes is also superimposed (source: GNS Science).

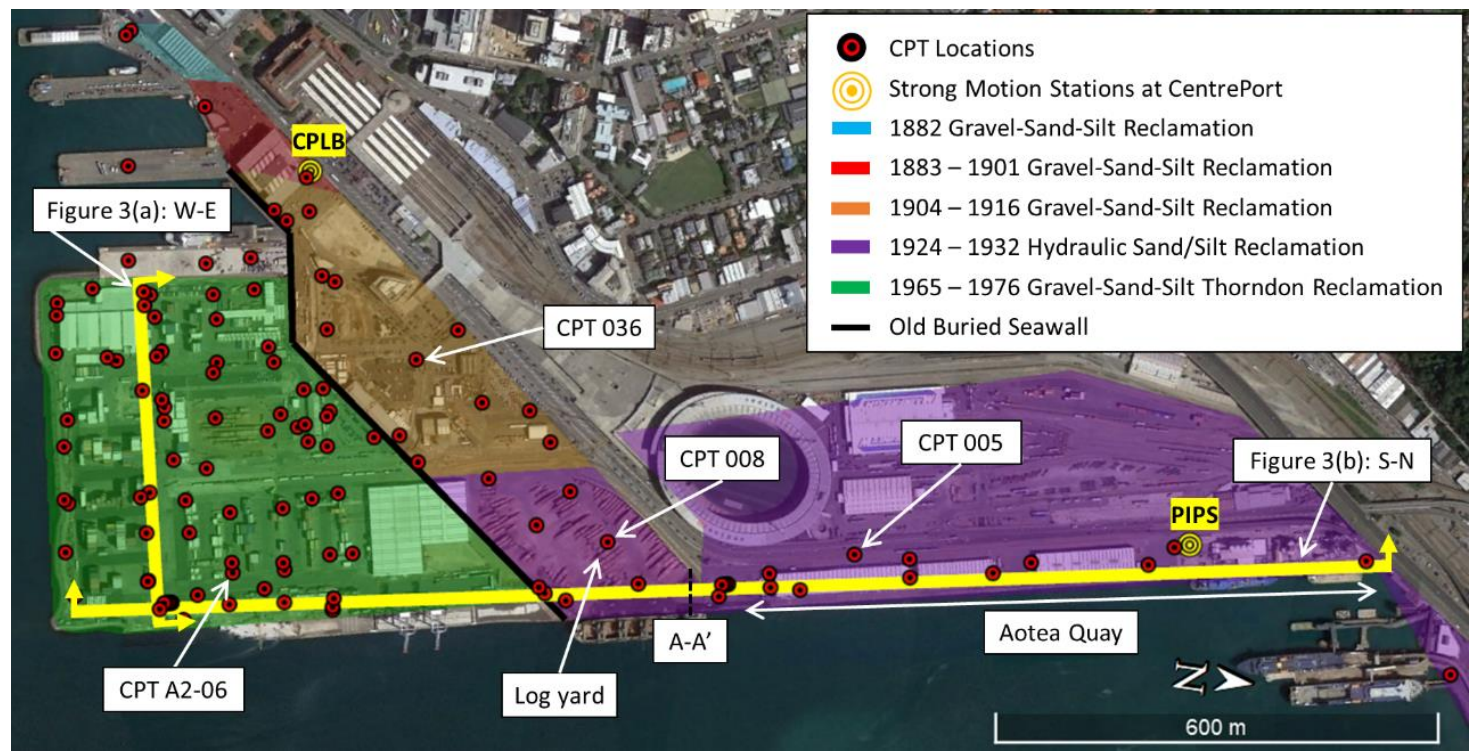

Figure 2: Aerial view of CentrePort showing reclamation zones, old buried seawall, location of strong motion stations CPLB and PIPS, locations of the 121 CPTs, labels of some CPTs referred to in Figure 5 and Figure 6, and two cross section transects (modified from [2]; base image from Google arth $^{T M}$ ).

Two methods of construction were used for the CentrePort reclamations. The 1924-1932 reclamation (purple shading in Figure 2) consists of hydraulic fills constructed using dredged material (sandy and silty soil) from the original seabed in the vicinity of the reclamation works. The remaining reclamations in the port were constructed by end-tipping of gravelly soil, sourced from nearby quarries, using truck and barge operations.

The top $3 \mathrm{~m}$ of the fill above the water table consist of a rollercompacted layer underlain by a thick uncompacted fill. In the older gravelly reclamation constructed between 1904-1916 (brown shading in Figure 2), the gravelly crust overlies 2-5 m of silty and sandy fill, which sits on top of 1-4 m of gravel reclamation. For the Thorndon reclamation (green shading in Figure 2), the thickness of the gravelly fill is generally between $10 \mathrm{~m}$ and $22 \mathrm{~m}$. Though the fill material in both reclamation zones is classified as gravelly (because it largely contains $>50 \%$ gravel-size particles), the soil composition also consists of at least $30 \%$ sand and silt fractions [3]. A relatively small region in the eastern part of the Thorndon reclamation contains a layer of sandy reclamation below the gravelly fill. In the hydraulic fills (purple shading in Figure 2), uncompacted marine soils dredged from nearby seabed make up the fill material up to depths of $10 \mathrm{~m}$. 
The fills sit atop a 1-4 m thick layer of Holocene beach material and marine sediments comprised of sand, clay, silty clay, all with shell fragments [1]. These marine sediments overlie Pleistocene weathered sediments (Wellington alluvium), approximately $90 \mathrm{~m}$ to $135 \mathrm{~m}$ thick. The Wellington alluvium is composed of interbedded dense gravels and stiff silts. Greywacke bedrock underlies the Pleistocene alluvium [3].

\section{EARTHQUAKE GROUND MOTIONS}

Three earthquakes with recorded ground motions are considered in this study. These events are the $M_{w} 6.6$ Cook Strait earthquake (21 July 2013), $M_{w} 6.6$ Lake Grassmere earthquake (16 August 2013), and the $M_{w} 7.8$ Kaikōura earthquake (14 November 2016). Of these events, the Kaikōura earthquake caused the most extensive damage to CentrePort, whereas minor damage was caused during the 2013 events, with a notable exception being the localised severe damage along the southmost edge of the fill at the Thorndon extension. The Kaikōura earthquake was caused by a complex rupture involving over 20 faults, which initiated at the southern end of the source zone and progressed northeast [4]. The approximate location of the source zones for these earthquakes are indicated in Figure 1. Also shown is the seismic activity for the 2013 earthquakes (due to the relatively complex rupture patterns compared to the scale of the figure, the seismic activity of the 2016 earthquake is omitted). The source-to-site distance $\left(R_{R U P}\right)$ was $44 \mathrm{~km}$ for the Cook Strait earthquake [5], $65 \mathrm{~km}$ for the Lake Grassmere earthquake [5], and $60 \mathrm{~km}$ for the Kaikōura earthquake [6].

Ground motions were recorded at several strong motion stations (SMS) in the vicinity of the port including records at a rock site, natural soil deposits, reclaimed sites atop shallow native deposits, and reclaimed sites atop deep natural deposits. The two SMS in the reclaimed land at CentrePort (CPLB and PIPS) are shown in Figure 2. CPLB is located in the 1904-1916 gravelly reclamation zone, and PIPS is located in an area of hydraulic fills.

The Cook Strait and Lake Grassmere earthquakes were of the same magnitude, and generally similar duration of shaking was felt at the port [6]. The Cook Strait earthquake generated higher horizontal peak ground accelerations (PGA) of $0.22 \mathrm{~g}$ at CPLB (no records were captured at PIPS for this earthquake) than the Lake Grassmere earthquake with horizontal PGAs of $0.15 \mathrm{~g}$ and $0.11 \mathrm{~g}$ at CPLB and PIPS, respectively. The $M_{w} 7.8$ Kaikōura earthquake produced longer duration of ground shaking of moderate amplitudes with horizontal PGAs of $0.25 \mathrm{~g}$ and $0.24 \mathrm{~g}$ at CPLB and PIPS, respectively. All PGA values are geometric means of north-south and east-west components of shaking.

The seismic demand for any given earthquake may vary over different reclamation zones in the port. Though CPLB and PIPS were not located at the south end of the port in the Thorndon reclamation where the most severe damage occurred, they are located on reclaimed land and hence incorporate ground motion amplification in the reclaimed deposits and basin-edge effects. This resulted in similar ground motion characteristics (intensity and duration) at both stations for the Kaikoura and Lake Grassmere earthquakes [7]. Therefore, these records appear to be representative of the seismic demand experienced by the reclaimed land during these earthquakes. Due to the absence of ground motions records at PIPS for the Cook Strait earthquake, and similar strong motion characteristics between the two SMS for the other two earthquakes, the analyses presented herein used available CPLB records as the seismic demand (i.e. PGA) for liquefaction analysis, for all three earthquakes. Sensitivity analyses regarding possible PGA variations throughout the port will be addressed in a subsequent publication.

\section{DETAILED SITE CHARACTERISATION}

Initially, CentrePort reclamations were characterised using 47 CPTs [6], shear wave velocity measurements [8], and preearthquake subsurface data from [9] and [10]. This study adds 74 CPTs successfully advanced in 2018 over two more phases of subsurface testing. The additional CPTs were performed with $10 \mathrm{~cm}^{2}$ and $15 \mathrm{~cm}^{2}$ A.P. van den Berg I-cones. Field operations involved a predrill to a depth of approximately $3 \mathrm{~m}$ through asphalt pavement and dense compacted gravelly fill crust to increase total cone penetration depth. If early refusal was encountered during a test at depths less than approximately $10 \mathrm{~m}, \mathrm{CPT}$ casing was extended beyond the refusal depth [11], and cone testing was then continued. The locations of all 121 CPT sites are shown in Figure 2.

Figure 3 schematically illustrates characteristic soil profiles along two cross sections (transects shown in Figure 2), for both the gravelly fill south of the seawall (Thorndon reclamation) and the hydraulic fills. These profiles summarise key features of reclamation soil units, the underlying marine sediments, and the Wellington Alluvium, as characterised by the CPTs. Traces of cone tip resistance $\left(q_{c}\right)$ for CPTs located along these cross sections are also included. Characteristic ranges $\left(25^{\text {th }}\right.$ and $75^{\text {th }}$ percentiles) of $q_{c}$ and soil behaviour type index ( $\left.I_{c}\right)$ values based on [12] are indicated in the plots for typical soil units. The vertical scale of the cross sections is exaggerated to emphasise important details, which distorts the geometry. The slope geometry and bathymetry are based on [10]. The unit thicknesses between CPTs have been interpolated based on boreholes and an interpretation of available data.

The gravelly fill is characterised by traces of relatively low tip resistance of $q_{c}=6.5-8.0 \mathrm{MPa}$ and $I_{c}$ values of $2.1-2.2\left(25^{\text {th }}\right.$ and $75^{\text {th }}$ percentiles). The uncompacted fill layer begins at a depth of $3 \mathrm{~m}$, coinciding with the approximate depth to water table. The thickness of the fill increases from about $10 \mathrm{~m}$ immediately south of the old buried seawall to approximately $22 \mathrm{~m}$ along the southern edge of the reclamation (called the Thorndon extension).

The relatively high values of $I_{c}$ for gravelly soil imply that these fills containing gravel-sand-silt mixtures display soil behaviour typical for silty sand. The CPT data indicate that the finer fractions (sand and silt) dominate the matrix, and hence, govern the response characteristics of the gravelly fill rather than the gravel-size particles $[3,13]$. The presence of loose-to-medium dense sand (i.e. $q_{c}$ above $10 \mathrm{MPa}$ ) below gravelly reclamation was a characteristic feature of the CPTs in the eastern part of the Thorndon reclamation where sandy ejecta was found on the ground surface following the Kaikoura earthquake. The depth to the sandy zone in the reclamation, as evidenced in the CPT traces, ranged from about $7 \mathrm{~m}$ to $20 \mathrm{~m}$, with thickness of the zone as large as $10 \mathrm{~m} \mathrm{[6].}$

The CPT data in the hydraulically-placed fill (Figure 3b) below the top compacted crust layer show relatively low penetration resistances up to depths of $5 \mathrm{~m}$ to $10 \mathrm{~m}$. The fill material was dredged from the original seabed and likely contains similar soil composition as the marine deposits (i.e. sand, silt, and clay). Two distinct soil types were characterised in the hydraulic fill from the CPTs: silty sand with $q_{c}=3.7-4.9 \mathrm{MPa}$ and $I_{c}$ around $2.0-2.1$; and, silt and clay with lower $q_{c}$ values below $2.0 \mathrm{MPa}$ and $I_{c}$ values above 2.6. These soil types were often deposited in intermittent layers (ranging from a few centimetres to several metres thick) with limited horizontal and vertical continuity. 


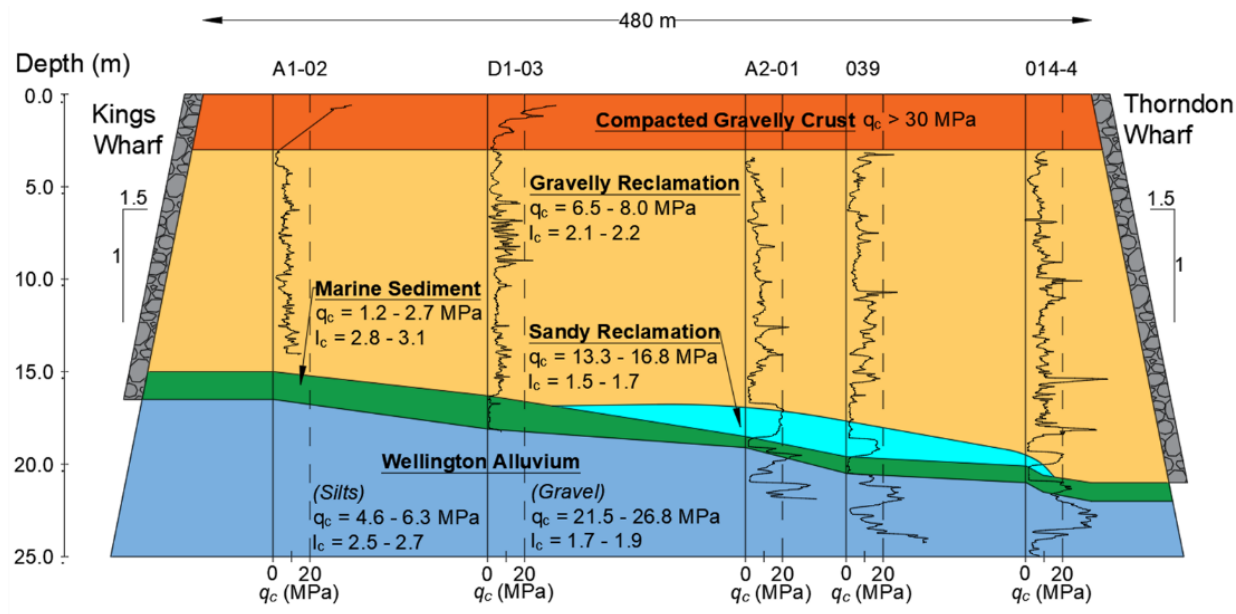

Distorted H:V Scale

(a) Cross-Section W-E

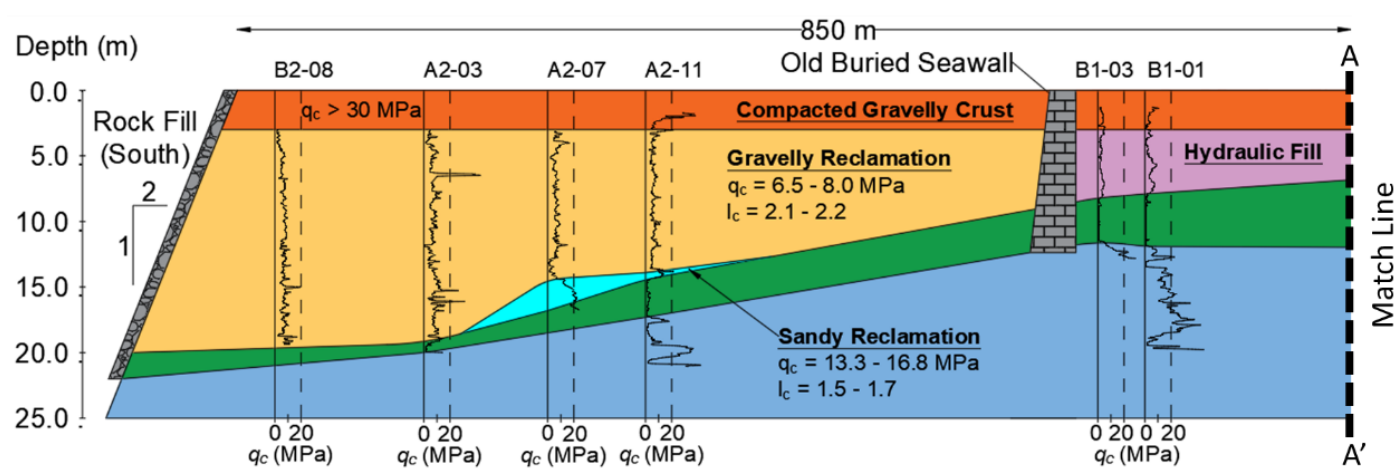

Distorted H:V Scale

(b1) Cross-Section S-N

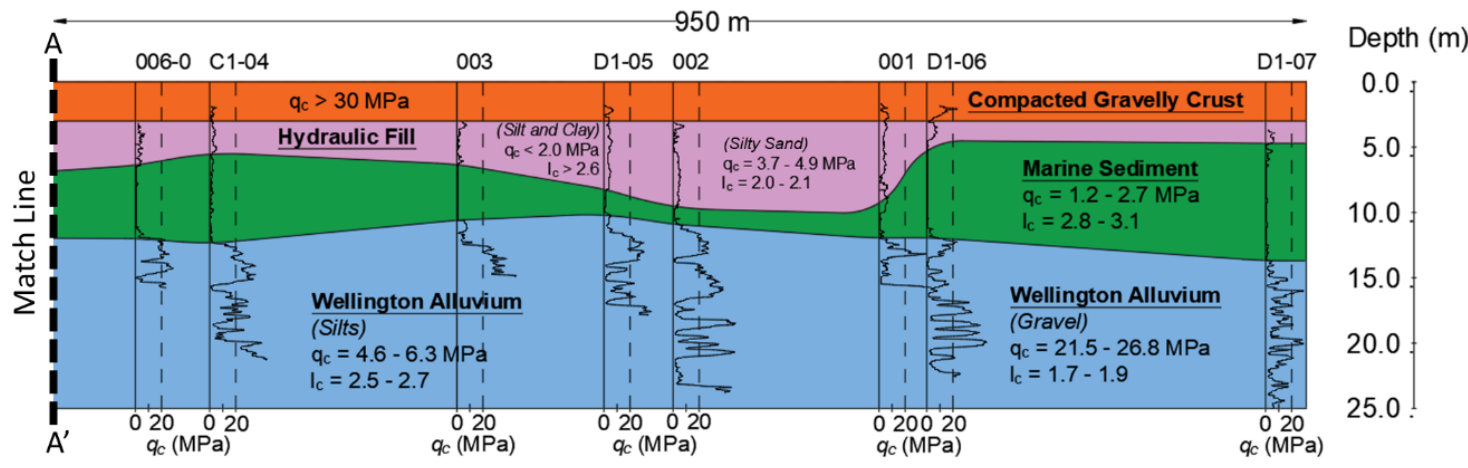

Distorted H:V Scale

(b2) Cross-Section S-N

Figure 3: (a) W-E and (b) $S$-N cross sections, modified from [14], depicting key soil units at CentrePort as characterised by CPTs (vertical scale exaggerated 10 times). The $S-N$ cross section is shown in two parts: (b1) Thorndon reclamation and log yard; (b2) Aotea Quay. See Figure 2 for cross section transects. The $q_{c}$ and $I_{c}$ ranges are based on $25^{\text {th }}$ to $75^{\text {th }}$ percentile values for each soil unit across all representative CPTs.

\section{OBSERVED LIQUEFACTION-INDUCED GROUND DEFORMATIONS}

Damage inspections following the 2013 earthquake sequence reported negligible damage caused by the Lake Grassmere earthquake over much of the port area. Most of the port also had minor damage reported after the Cook Strait earthquake, with a notable exception being the localised severe damage and partial collapse of the southmost edge of the Thorndon reclamation [5]. Lateral movement of approximately $250 \mathrm{~mm}$ at King's wharf (western end of the Thorndon reclamation) and over $100 \mathrm{~mm}$ along the south road was reported. Cracks were evident at the east and west edges of the reclamation adjoining King's Wharf and Thorndon Container Wharf (TCW). Vertical settlements around $50 \mathrm{~mm}$ (and as large as $90 \mathrm{~mm}$ ) were observed after the Cook Strait earthquake, but little wharf damage and ground deformations were reported to have occurred due to the Lake Grassmere shaking. The Cook Strait earthquake was reported to have caused some liquefaction-induced damage, with ejecta trace observed at four locations, while no major damage was reported from the Lake Grassmere earthquake. Temporary erosion works were performed along the southern edge of the fill to mitigate further erosion after the earthquakes. In addition, the southern slope along Thorndon extension was reshaped to a gentler slope of $2 \mathrm{H}: 1 \mathrm{~V}$, and the protection layer was riprapped. However, there was no ground improvement of the reclamations.

In contrast, the 2016 Kaikōura earthquake triggered widespread liquefaction and consequently severely damaged buildings and wharves. The most severe damage occurred in the Thorndon reclamation where non-uniform and scattered liquefaction ejecta were observed on pavement surface of the port including traces of ejected silt and water to larger volumes of gravelly ejecta of thicknesses up to $150-200 \mathrm{~mm}$. Global deformation involved approximately $1 \mathrm{~m}$ horizontal movement of the 
reclamation slopes (edges) in outward (seaward) directions, with characteristic liquefaction-induced lateral spread cracking and ground distress progressing in-land within the reclamation. Large vertical offsets on the order of hundreds of millimetres to above half a meter were observed between pile supported wharves and buildings and their surrounding ground $[3,6]$.

During the Kaikōura earthquake, the area containing hydraulic fills along Aotea Quay had some ground distress including cracks parallel to the revetment line, but no soil ejecta were observed. The hydraulic fills in the log yard liquefied with sand and silt ejecta manifesting through ground cracks, and vertical movement as large as $200 \mathrm{~mm}$ was measured. In the older 19041916 gravelly reclamation, a small area of gravelly and sandy ejecta trace was observed immediately north of the buried seawall. Ground cracks in this area were generally $<75 \mathrm{~mm}$ in width, and severe damage occurred to buildings supported on deep foundations.

Further details of the vertical and lateral ground deformations, liquefaction manifestation and associated damage to structures can be found in [3]. Mapping of the observed ejecta trace distribution, major cracks, demolished buildings and substantially damaged port structures due to the 2016 Kaikōura and 2013 Cook Strait earthquakes are summarised in Figure 4 $[5,15]$.

\section{SIMPLIFIED LIQUEFACTION ASSESSMENT}

\section{Analysis Procedure}

The collected CPT data were used to evaluate liquefaction triggering and its consequences using simplified liquefaction assessment procedures for a free-field level ground condition. The groundwater level estimates at the time of conducting the CPTs were based on tape measurements of the water level taken after pre-drill and before conducting the CPT. Water levels tend to vary as the tide level changes (up to $\pm 1 \mathrm{~m}$ ) at CentrePort, and the variation in the water level inland usually has a time lag with the actual tidal pattern. To account for these effects in the liquefaction analyses, tidal data from nearby piezometers were back-analysed to account for daily and seasonal variation in estimating the water level at the CPTs at the time of the earthquakes. Water table depths at the time of the earthquakes were $3.0-3.5 \mathrm{~m}\left(25^{\text {th }}\right.$ and $75^{\text {th }}$ percentiles $)$, which was typically 0.2-0.8 m greater than the depths established at the time of CPT field investigations due to the relatively low tide during all three earthquakes.

Grain-size distribution curves of borehole soil samples of the gravelly reclamation and ejecta samples from the same area (collected before and after the earthquakes) show a relatively narrow range of fines content $(F C)$ of 5-20\% [2,3,6]. Even though liquefaction triggering analyses are sensitive to $F C$ in this range of values, liquefaction is estimated to occur and produce similar consequences in the gravelly reclamation for both $F C$ values of $5 \%$ and $20 \%$. Hence, liquefaction triggering analyses of the gravelly fill are performed with a representative $F C$ value of $15 \%$. As for the hydraulic fills, the CPTs characterised two distinct soil behaviour types: silty sand with $I_{c}$ around $2.0-2.1$, and silt and clay with $I_{c}>2.6$. These soil behaviour types are often found in layers ranging from a few centimetres to several metres thick, and are sometimes found mixed together. Representative $F C$ values for these soils are not known due to limited soil samples collected and inherent difficulty in characterising thin layers using the CPT. Therefore, the Boulanger and Idriss [16] $F C-I_{C}$ correlation with $C_{F C}=0$ is applied to the hydraulic fills. The details of comprehensive sensitivity analyses on $F C$ and $C_{F C}$ will be presented in a subsequent publication.

The conventionally adopted soil behaviour type index $\left(I_{c}\right)$ criterion of $I_{c}<2.6$ from [12] was used to identify soils susceptible to liquefaction. The moment magnitudes $\left(M_{w}\right)$ and geomean horizontal PGAs for the three earthquakes summarised previously were used as the seismic demand parameters. Liquefaction triggering was evaluated using the Boulanger and Idriss [16] CPT-based procedure (BI2014) to calculate the factor of safety against liquefaction triggering. The probability of liquefaction triggering $\left(P_{L}\right)$ of $50 \%$ was used for the back-analysis of this case history instead of using a conservatively biased deterministic design value of $P_{L}=16 \%$. The Zhang et al. [17] procedure was used to estimate postliquefaction reconsolidation settlement.

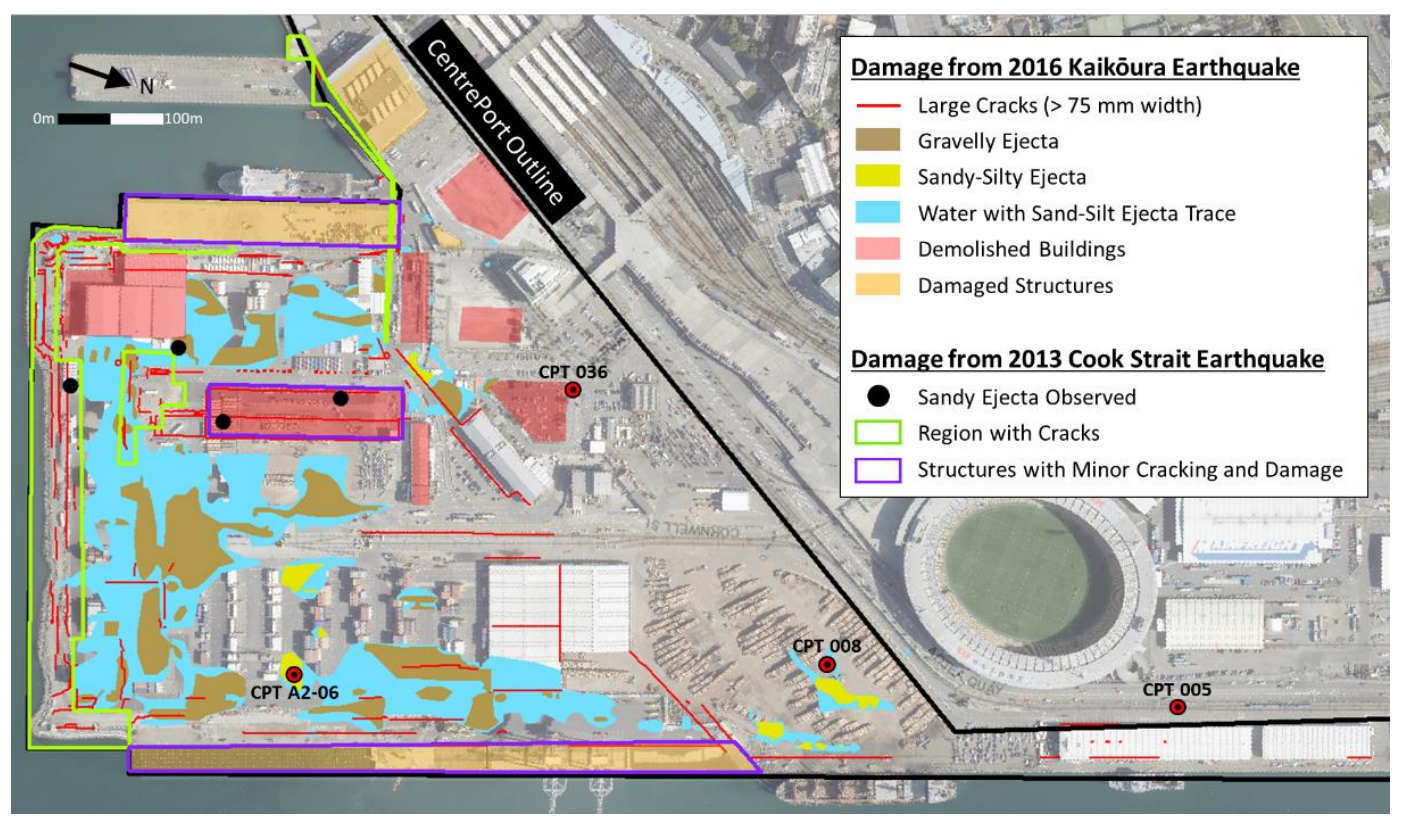

Figure 4: Map highlighting key damage from the 2016 Kaikōura earthquake (ejecta manifestation, major cracks, demolished buildings, and substantially damaged structures) and the 2013 Cook Strait earthquake (locations of observed sandy ejecta trace, regions with observed cracks, and structures with minor cracking and damage) within CentrePort [5, 15]. The areas within CentrePort beyond the area shown by this map had no ejecta trace and large cracks (> $75 \mathrm{~mm}$ width) and was therefore omitted. 

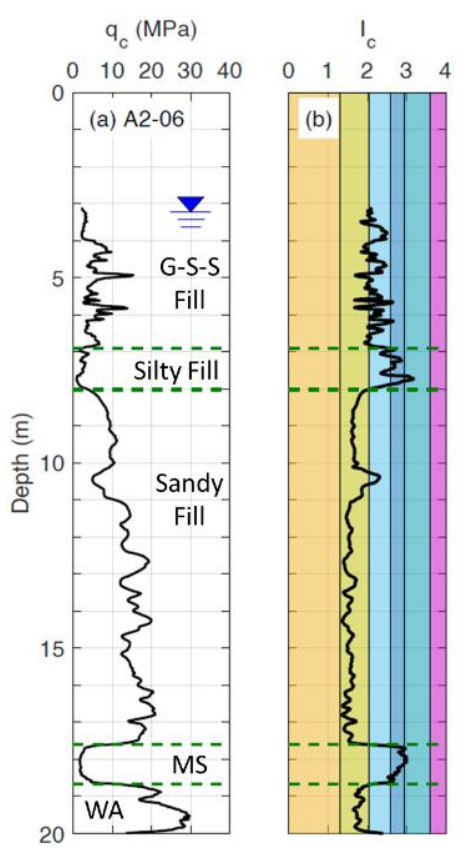

CRR and CSR

$0 \quad 0.10 .20 .30 .4$

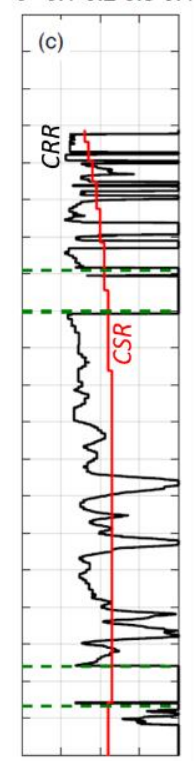

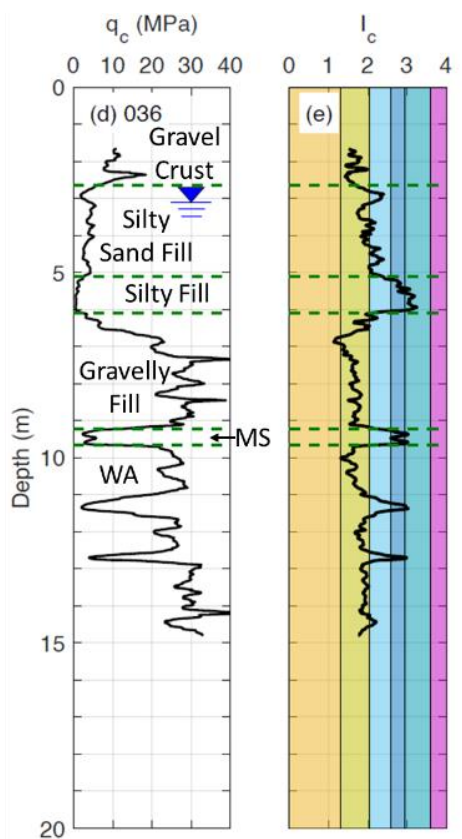

CRR and CSR

0.10 .20 .30 .4

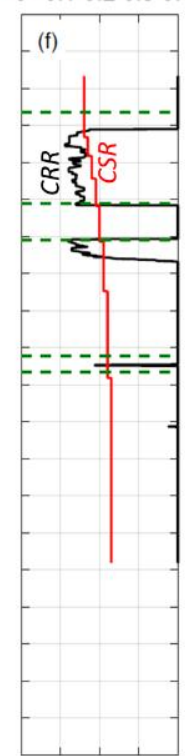

Figure 5: CPT cone tip resistance ( $\left.q_{c}\right)$, soil behaviour type index ( $\left.I_{c}\right)$, cyclic resistance ratio (CRR), and cyclic stress ratio (CSR) profiles calculated with the Boulanger and Idriss [16] procedure under the seismic demand of the 2016 Kaikoura earthquake for CPT A2-06 (a, b, c) and CPT $036(d, e, f) . G-S-S$ denotes gravel-sand-silt mixture, MS denotes marine sediments, and WA denotes Wellington alluvium.
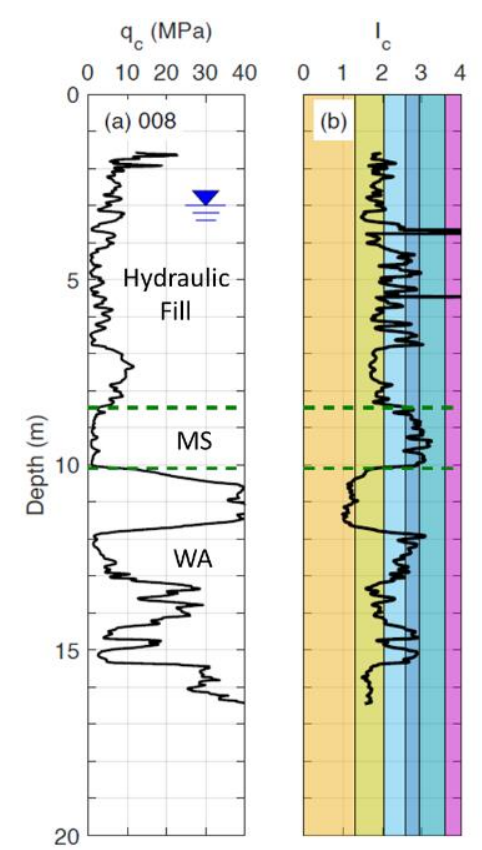

CRR and CSR

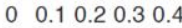

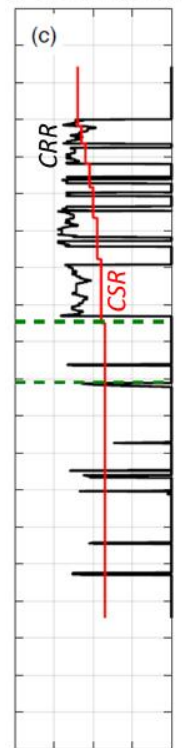

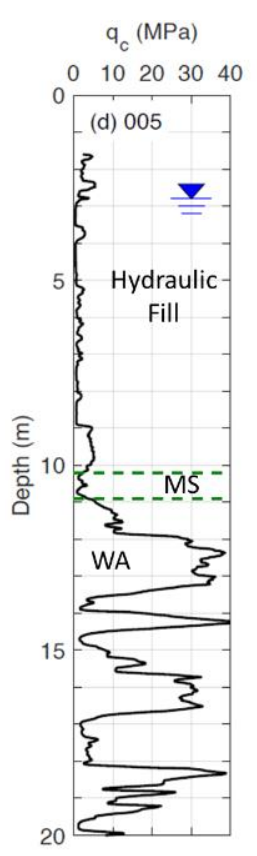

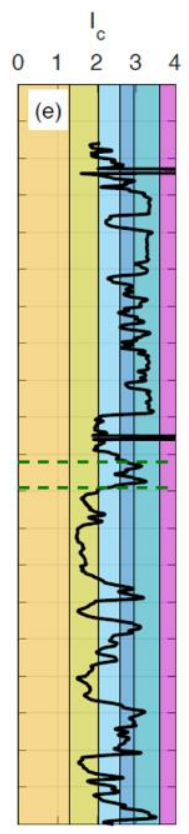

CRR and CSR

$\begin{array}{lllll}0 & 0.1 & 0.2 & 0.3 & 0.4\end{array}$

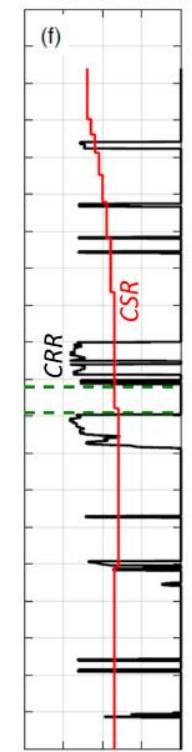

Figure 6: CPT cone tip resistance ( $\left.q_{c}\right)$, soil behaviour type index $\left(I_{c}\right)$, cyclic resistance ratio (CRR), and cyclic stress ratio (CSR) profiles calculated with the Boulanger and Idriss [16] procedure under the seismic demand of the 2016 Kaikoura earthquake for CPT $008(a, b, c)$ and CPT $005(d, e, f)$. MS denotes marine sediments and WA denotes Wellington alluvium.

\section{Triggering Analysis for the 2016 Kaikōura Earthquake}

\section{Representative Profiles}

Results of the analysis for representative profiles from different reclamation zones for the 2016 Kaikōura earthquake are shown in Figure 5 and Figure 6. Figure 5 shows two profiles from regions with gravelly reclamation fill atop the marine sediments and alluvium. CPT A2-06 represents one of the few areas in the Thorndon reclamation where gravel fills are atop sandy reclamation, below which is marine sediment and Wellington alluvium. CPT 036 represents a site with fills containing mixtures of sands and silts, with small fraction of gravels, deposited atop native marine sediment during the period of 1904 to 1916.
Two representative profiles for the hydraulic fill are shown in Figure 6. CPT 008 represents a site at the log yard, where sandy ejecta was observed, containing hydraulic fills up to $8.5 \mathrm{~m}$ depth deposited between 1924 and 1932. CPT 005 also contains hydraulic fills deposited during the same period, but the site is located along Aotea Quay where no liquefaction ejecta trace was observed on the ground surface.

Profiles of $q_{c}$ and $I_{c}$, followed by the computed $C R R$, corrected using magnitude scaling factor $(M S F)$ based on the Kaikōura earthquake moment magnitude, and $C S R$ profiles are shown for CPT A2-06 in Figure $5 \mathrm{a}, 5 \mathrm{~b}$ and $5 \mathrm{c}$. The results of the simplified liquefaction evaluation procedure indicate the $50^{\text {th }}$ percentile $C R R$ of the reclamation is below the seismic demand of the 2016 Kaikōura earthquake (i.e. its CSRs). Hence, the 
Boulanger and Idriss [16] CPT-based simplified procedure indicates that liquefaction should have been triggered at this CPT for both the sandy reclamation and the gravelly fill under the seismic demand of the Kaikoura earthquake. Examining this CPT profile closely, there are several spikes in $q_{c}$ (for example at depths of $5 \mathrm{~m}$ and $5.8 \mathrm{~m}$ ), which lead to reduced $I_{c}$ and increased $C R R$ values. The isolated spikes in $q_{c}$ are not reflective of the overall response of the soil. Instead, the spikes reflect a sudden increase in soil resistance due to interaction of the cone tip with gravel-sized particles and are representative of the highly variable and complex soil composition of the gravelsand-silt mixture.

As discussed previously, the $I_{c}$ range for the gravel fill suggest it is susceptible to liquefaction. The CPT data in these fills are influenced primarily by the sand-sized and silt-sized particles forming the matrix of the reclamation despite a majority of the soil particles (by weight) being gravel-sized. The CPT-based analysis can characterise the observed seismic performance of the end-dumped gravelly fills of the Thorndon reclamation with their sand-silt matrix. Hence, the liquefaction analysis is producing results consistent with the observed severe liquefaction-induced damage in the Thorndon reclamation.

There is a small $1 \mathrm{~m}$ layer of silty fill typically found sitting between the gravelly fill and sandy reclamation. These layers have high $I_{c}$ values above 2.6 and are therefore non-liquefiable. The sandy reclamation below the gravelly reclamation and silty fill is well-characterised by the measured $q_{c}$ values between $10 \mathrm{MPa}$ (lower density fill) and $20 \mathrm{MPa}$ (higher density fill), which also lead to $C R R$ values that are generally below the $C S R$ developed during the 2016 Kaikōura earthquake indicating that the sandy zone within the reclamation should have liquefied.

Profiles of $q_{c}, I_{c}, C R R$ (MSF corrected based on the Kaikōura earthquake) and CSR are shown for CPT 036 in Figure $5 \mathrm{~d}, 5 \mathrm{e}$ and $5 \mathrm{f}$. Below the gravelly crust is a $2 \mathrm{~m}$ layer of silty sand reclamation where $C R R$ values are below the $C S R$ for the Kaikōura earthquake. This layer sat atop a $1 \mathrm{~m}$ layer of nonliquefiable silt with $I_{c}$ close to 3.0 . From $6 \mathrm{~m}$ to $9 \mathrm{~m}$ depth is then another layer of dense gravelly reclamation where $C R R$ is largely above $C S R$. The thickness of soil estimated to liquefy by the Boulanger and Idriss [16] CPT-based analysis is much less than the Thorndon reclamation profile, indicating less severe liquefaction in this older reclamation. This is consistent with observed small cracking and damage to buildings on deep foundation in this reclamation zone, but lack of thick liquefaction ejecta trace observed.

Figure 6 shows two profiles containing sandy hydraulic fills (layers with $q_{c}$ around $4 \mathrm{MPa}$ and $I_{c}$ values of approximately 2.0) also characterised by low $C R R$ traces compared to the $C S R$ estimates for the Kaikōura earthquake. The hydraulic fills were constructed approximately 90 years ago by slurry deposition of seabed materials with no compaction below the water table. The sandy soil layers of the hydraulic fill are relatively young and loose with a weak soil fabric, all of which contributed to poor performance during the 2016 Kaikōura earthquake in areas of the hydraulic fill where such sandy soil layers were prevalent.

There is variability in the amount of fines contained in the sand within the hydraulic fills, which in turn affects their estimated liquefaction resistance. CPT 008 (Figure 6a, 6b and 6c) contains thicker cumulative liquefiable sandy layers, indicating more severe liquefaction triggering at this site. This is consistent with the large volumes of sandy ejecta observed at the $\log$ yard. The hydraulic fills in CPT 005 (Figure $6 \mathrm{~d}, 6 \mathrm{e}$ and $6 \mathrm{f}$ ) have a greater percentage of non-liquefiable silts and clays with $I_{c}>2.6$. Therefore, majority of the fill deposits in this profile are non-liquefiable, which is consistent with the lack of ejecta manifestation observed on the ground surface following the Kaikōura earthquake.

\section{Triggering Analysis of all CPT Profiles}

Liquefaction triggering assessment for the three reclamation zones of interest under the seismic demand of the 2016 Kaikōura earthquake is shown in Figure 7 in terms of the cyclic stress ratio (normalised for $M_{w}=7.5$ and $\sigma_{v}^{\prime}=100 \mathrm{kPa}$, denoted as $C S R 7.5$ ) as a function of the clean sand-equivalent corrected cone tip resistance $\left(q_{c l N c s}\right)$. Each point represents the median $q_{c I N c s}$ and $C S R 7.5$ in the critical layer for a single CPT location. Only CPTs within the three reclamation zones shown were used. CPTs near boundaries between reclamation zones which created significant ambiguity in identifying its associated reclamation history were also removed. A total of 107 CPTs were therefore analysed. The Boulanger and Idriss cyclic resistance ratio $(C R R)$ curves [16] for $P_{L}$ of $16 \%, 50 \%$ and $84 \%$ are also plotted for reference. Note that the deterministic curve (conventionally used in forward assessment) is for $P_{L}=16 \%$, but in this analysis $P_{L}=50 \%$ was used for back-analysis of case history. The factor of safety, denoted as $F S_{50}$, was calculated by normalising $C R R$ for $P_{L}=50 \%$ by $C S R 7.5$. The minimum and maximum $\mathrm{FS}_{50}$ for this set of CPT profiles are also illustrated in Figure 7.

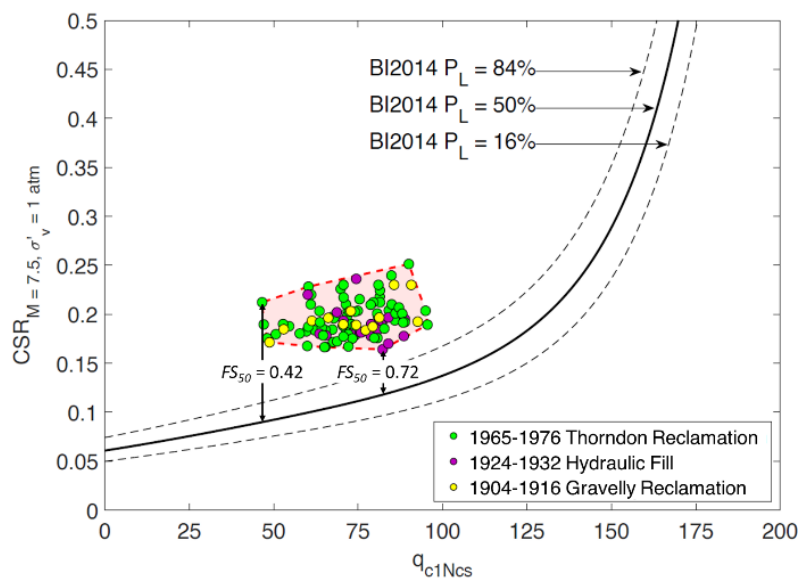

Figure 7: Results of the simplified triggering analysis for CPT profiles for the 2016 Kaikoura earthquake.

$F S_{50}$ for the critical layers range from 0.42 to 0.72 for all three reclamation zones using the Boulanger and Idriss CPT-based simplified procedure [16] with $P_{L}=50 \%$. These factors of safety $\left(F S_{50}<1.0\right)$ indicate that liquefaction should have been triggered in the critical layers at all CPT sites, and over all three reclamation zones at CentrePort under the seismic demand of the Kaikōura earthquake. As discussed previously, liquefaction effects (e.g. soil ejecta, and vertical and horizontal ground movements) were observed across much of the port after this event. Thus, the simplified CPT-based liquefaction triggering procedures provide results generally consistent with the field observations for most of these sites.

However, the estimated extent and severity of damage across the different reclamation zones were not consistent with observations. Lack of liquefaction ejecta manifestation in the hydraulic fills and older 1904-1916 gravelly reclamation was in stark contrast to the thick volumes of soil ejecta in the Thorndon reclamation. Furthermore, reduced settlements, smaller cracks, and less lateral movement suggests the severity of liquefaction in the rest of the port was much less than at the Thorndon reclamation. The triggering analysis estimates a similar range of $F_{50}$ values for the critical layers of CPTs in all three reclamation zones and is therefore unable to discern the differences between the severity of the liquefaction-induced damage across the port. 


\section{Comparison to Observations}

In this paper, CPT profiles near ground settlement observations are first used to compare one-to-one and then to investigate local differences between observed and calculated settlements. As liquefaction often manifests by exploiting weak links in the soil deposit [18], it is possible that global features in the response and interactions with surrounding soils may have contributed to the observed settlements at a specific location. Therefore, overall global trends in observed and computed settlements will also be investigated to facilitate such comparisons.

Figure 8 compares the estimated one-dimensional postliquefaction volumetric-induced settlements for the Kaikōura earthquake, based on Zhang et al. [17], to the settlement measurements from aerial surveys for all CPTs located within $10 \mathrm{~m}$ of the measured vertical displacement survey points. Aerial survey data with accurate settlement measurements do not exist for the 2013 Cook Strait and Lake Grassmere earthquakes so this type of analysis is not possible for the 2013 earthquakes.

The estimated settlements for the Kaikōura earthquake are generally smaller than the vertical displacements measured at these locations, however, they are reasonably close to the measured settlement at most locations. Consistent underestimation of the measured settlement occurred at CPT locations close to the reclamation edges, while the calculated estimates appear to perform better for CPTs in free-field conditions (> $60 \mathrm{~m}$ from the edges). The difference between measured and calculated settlements are greatest for CPTs $<25 \mathrm{~m}$ to the edge (e.g. CPTs A1-08, A1-05 and A1-06). Note that lateral-spreading induced ground movements may have contributed to additional settlements near the edges of the reclamation. Strictly speaking, the Zhang et al. [17] simplified method evaluates post-liquefaction volumetric settlements assuming free-field level ground conditions, and hence is appropriate for sites away from the reclamation edges that are not affected by lateral spreading.

In addition to the insights provided from direct comparisons of estimated to measured settlements at particular locations, estimated settlements are also compared against observations on a global scale. Figure $9 \mathrm{c}$ and $9 \mathrm{~d}$ illustrates the spatial distribution of the estimated liquefaction-induced settlements and measured vertical displacements at aerial survey points (including measurements shown in Figure 8). Results from the triggering analyses are also shown in the form of damage indices $L S N$ [20] and $L P I$ [21] in Figure 9a and 9b respectively.
The natural neighbour interpolation method proposed was used to produce contours of damage indices and settlements [22].

$L S N$ and $L P I$ tend to increase for areas with thicker reclamation fills, predominantly at the southern end of the Thorndon reclamation. These trends are correctly suggesting the severity of liquefaction increases towards the south, which is consistent with observations. The damage indices are showing trends which were not evident in the triggering analyses results presented previously. However, the non-uniformity observed in the ejecta trace is not replicated in these $L S N$ and $L P I$ contours. There are several potential factors contributing to these discrepancies such as the fill characteristics (i.e. changes in material composition), the integrity of the crust and paved areas, effects of lateral spreading or interaction with buried wharf and building structures which may also contribute to the extent of liquefaction-induced damage observed [23].

The estimated settlements generally follow a similar trend to the $L P I$ and $L S N$ contours. The performance of the eastern part of the Thorndon reclamation is interesting. The calculated settlements are in the range of $0-100 \mathrm{~mm}$ in this area, which is less than the surrounding areas which were estimated to have settled $>150 \mathrm{~mm}$. A slight reduction in the measured vertical settlement is also observed from the aerial surveys (100$200 \mathrm{~mm}$ settlements) compared to the surrounding areas (> $200 \mathrm{~mm}$ settlement). This region was located near CPT 018, which [2] showed as the only CPT in the Thorndon reclamation with an extra 4-5 m (i.e. total 7-8 m) of non-liquefiable crust $\left(I_{c}>2.60\right)$ above the gravelly fill. The presence of a thicker non-liquefiable crust reduces two components of settlement: total volumetric settlement is reduced as the total thickness of liquefied soil decreases; and vertical movement due to loss of soil from ejecta also reduces as liquefied soil is not able to penetrate through the thicker non-liquefiable crust. The Zhang et al. [17] simplified procedure considers the first of these two settlement components, and possibly captured this effect resulting in the reduction in estimated post-liquefaction volumetric settlement for this area.

Inconsistencies in the estimations compared to the measured ground settlement trends also exist reflecting various simplifications adopted in the simplified analysis regarding material characteristics and liquefaction resistance of complex soil mixtures, and interactions within liquefying fills. Also, global deformation effects including lateral spreading and interactions with buried structures and buildings on shallow and deep foundations are not captured in these simplified procedures.

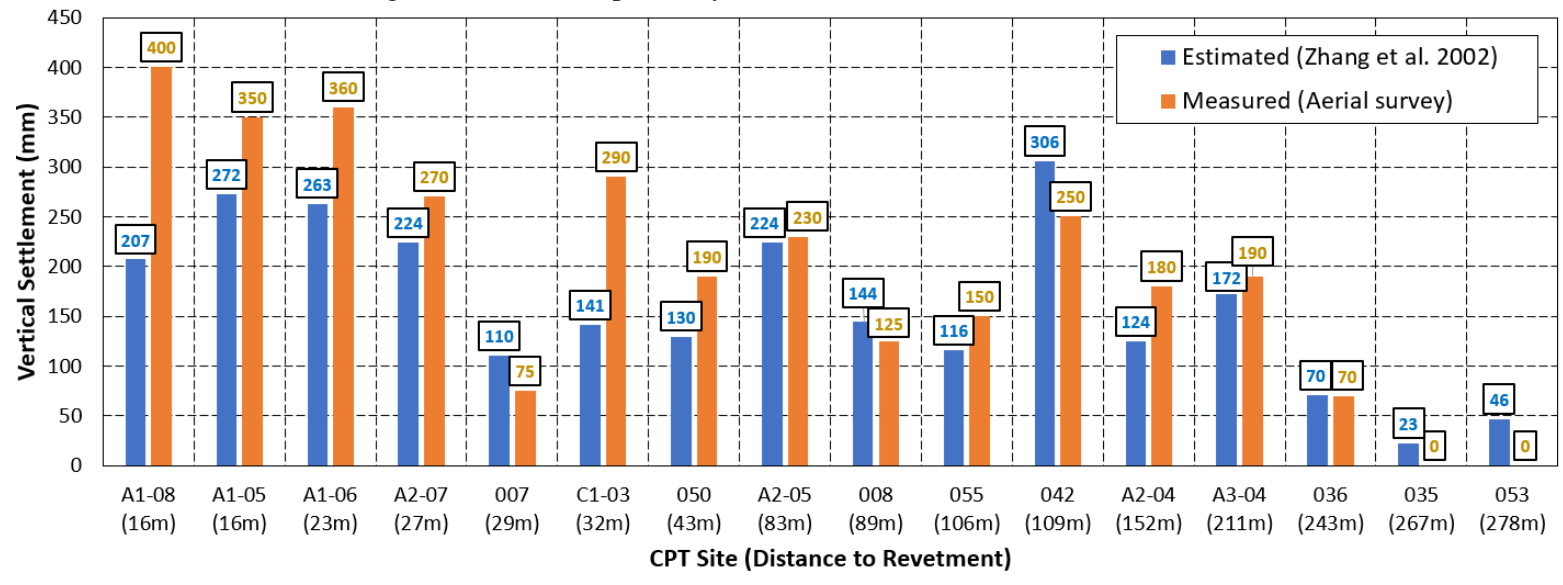

Figure 8: Settlements estimated using the Zhang et al. [17] procedure compared to measured vertical displacements from aerial surveys (errors up to $\pm 75 \mathrm{~mm}$ ) at 16 CPT sites where observation points were $<10 \mathrm{~m}$ from the CPT locations for the 2016 Kaikōura earthquake (modified from [19]). 

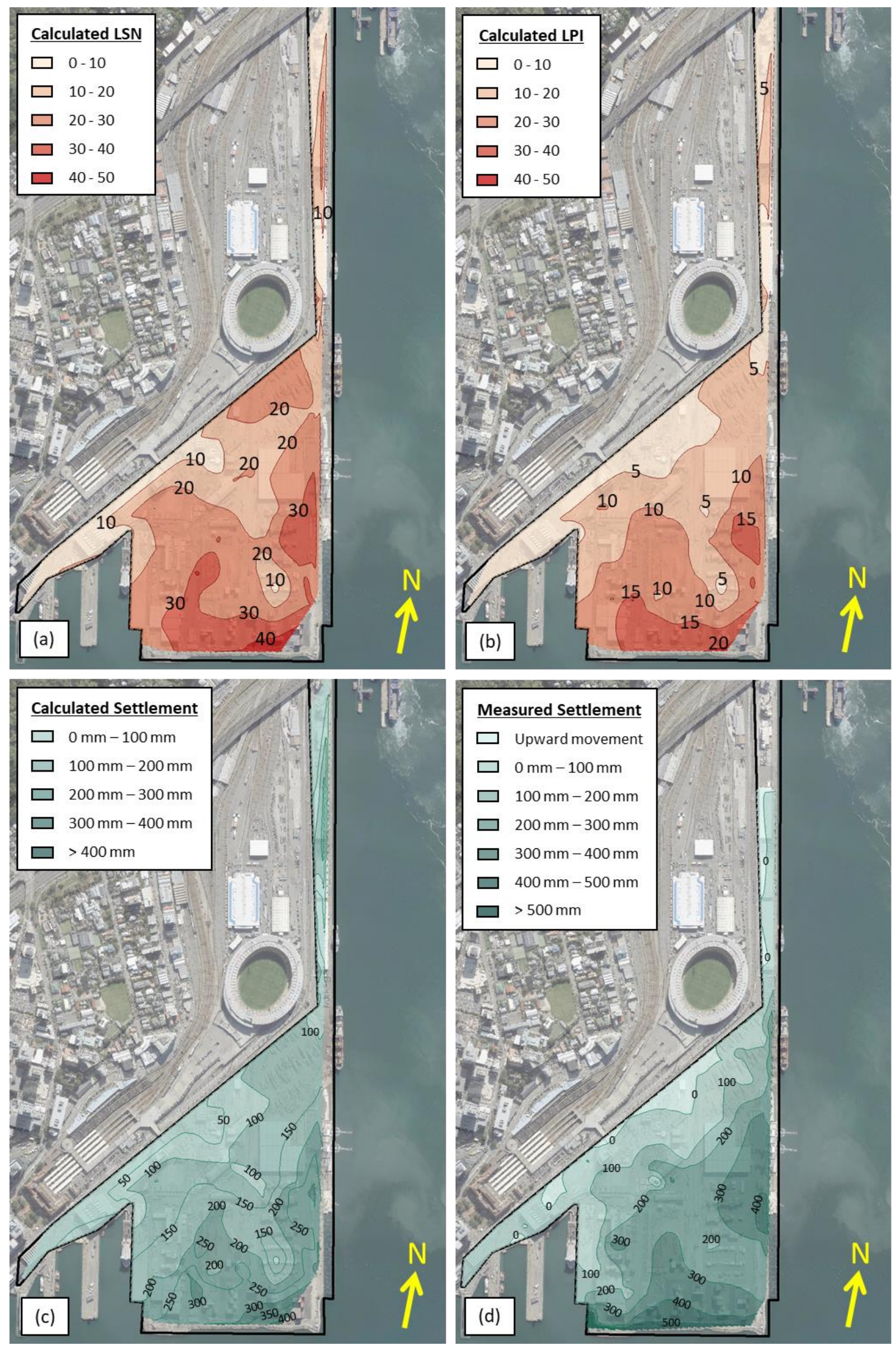

Figure 9: Spatial distribution of: (a) Calculated Liquefaction Severity Number (LSN); (b) Calculated Liquefaction Potential Index (LPI); (c) Calculated vertical settlement estimates; and (d) Measured vertical movement (point measurement errors up to $\pm 75 \mathrm{~mm}$ ) based on aerial surveys, all for the 2016 Kaikoura earthquake. 


\section{Triggering Analysis for Multiple Earthquakes}

\section{Triggering Analysis of all CPT Profiles}

Liquefaction assessment under the seismic demand of the Cook Strait and Lake Grassmere earthquakes was also conducted for the same set of CPTs across the three reclamation zones of interest. The range of $C_{S R} 7.5$ and associated $q_{c 1 N c s}$ values for the critical layers of all CPTs for the three earthquakes considered are shown in Figure 10. The Boulanger and Idriss [16] CRR curves for $P_{L}$ of $16 \%, 50 \%$ and $84 \%$ are plotted for reference.

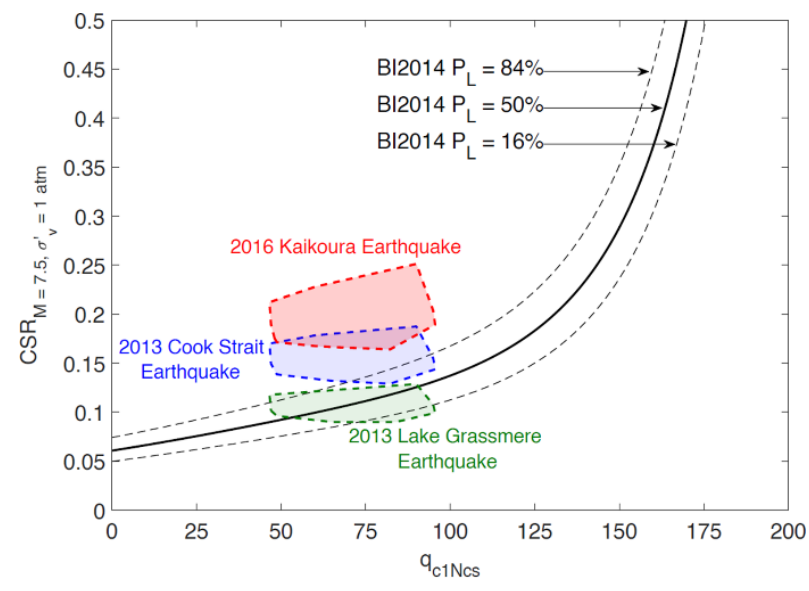

Figure 10: Results of the simplified liquefaction triggering analysis for CPT profiles for the 2016 Kaikoura and the 2013 Cook Strait and Lake Grassmere earthquakes shown as general ranges of median CSR 7.5 and $q_{c 1 N c s}$ at each profile.

Results from these liquefaction triggering analyses show that critical layers in most profiles had median $\operatorname{CSR}_{7.5}$ values above the $P_{L}=50 \%$ triggering curve for the seismic demand of the Cook Strait earthquake. This is generally inconsistent with observations that majority of the port had minor or no damage, with the exception of partial collapse of the slope at the southern end of the Thorndon reclamation [5]. Note this earthquake had a similar PGA as the Kaikoura earthquake, so the moment magnitudes primarily contributed to the different seismic demands, according to the simplified characterisation of earthquake loading in the liquefaction triggering analysis.

Only approximately $50 \%$ of the CPT profiles were estimated to liquefy under the demand of the Lake Grassmere earthquake. This earthquake had a similar moment magnitude as the Cook Strait earthquake, so the differing levels of PGA contributed primarily to the different seismic demands. The Lake Grassmere earthquake was reported to have caused only minor cracking $(<50 \mathrm{~mm})$ at some locations; it largely caused no damage. Hence, the simplified procedure is correctly estimating no liquefaction triggering for approximately $50 \%$ of the profiles, but it is overestimating the extent of liquefaction damage for the remaining 50\% CPT profiles.

\section{Comparison to Observations}

Figure 11 shows the range of estimated one-dimensional postliquefaction settlement for the three earthquakes over a range of CPT sites using the Zhang et al. [17] procedure. The range of observed settlement is also included to facilitate comparisons.

The simplified liquefaction procedure captures reasonably well the liquefaction-induced ground settlement for the moderate and low levels of shaking intensities of the Kaikoura and Lake Grassmere earthquakes, respectively. The range of estimated settlements for both events is slightly lower than the range of observed settlement at CentrePort. This is reasonable if one considers that simplified settlement estimates only considers post-liquefaction volumetric settlements and do not account for vertical settlements due to loss of soil from ejecta and lateral spreading-induced deformation.

The amplitude of shaking for the Cook Strait earthquake was higher than the Lake Grassmere earthquake and closer to the Kaikōura earthquake, as indicated by the similar levels of PGA. However, the moment magnitude for the Cook Strait earthquake was approximately the same as the Lake Grassmere, indicating the duration of shaking was much less than the Kaikoura earthquake. Thus, the seismic demand induced by the Cook Strait earthquake is between the other two events.

The calculated ground settlement from the simplified analysis for the Cook Strait earthquake appear to overestimate slightly to moderately the observed settlement. Hence, the simplified procedure captures field observations better for the high and low seismic demands of the Kaikōura and Lake Grassmere earthquakes at CentrePort, in which severe and no/minor liquefaction effects respectively were observed, and largely correctly estimated. Conversely, the estimates are poorer at capturing the field observations for the Cook Strait earthquake, which produced a seismic demand relatively close to the liquefaction triggering thresholds for the fills, and therefore, these estimates are more sensitive to the accuracy of the simplified method in correctly predicting liquefaction triggering.

\section{CONCLUSION}

Recent seismic activity has caused different levels of liquefaction-induced damage in the end-dumped gravelly fills and hydraulically-placed sandy and silty fills at CentrePort in Wellington, New Zealand. The complex soil composition, fabric, and structure of the reclamations pose challenges with regard to obtaining quality subsurface geotechnical data and assessing the liquefaction performance of the soil using stateof-the-practice simplified methods. Recognising these difficulties, comprehensive field investigations with robust CPT equipment and procedures were performed to obtain highquality subsurface data to enable liquefaction triggering and post-liquefaction reconsolidation settlement assessments.

Simplified CPT-based liquefaction triggering analyses indicate the procedure can estimate reliably liquefaction triggering for most of the port under the seismic demand for the 2016 Kaikōura earthquake. The CPTs were able to capture the influence of the finer silt and sand matrix of the Thorndon reclamation, thus leading to CPT-based liquefaction analysis correctly estimating liquefaction triggering consistent with observations. The estimated post-liquefaction volumetric settlements are underestimated only slightly for free-field areas away from lateral spreading. Observed vertical ground movements increased in the areas of lateral spreading, but these effects are beyond the scope of settlement estimates based on the simplified liquefaction evaluation procedure.

The simplified procedures estimate no triggering of liquefaction for $50 \%$ of the CPTs in the port under the seismic demand of the 2013 Lake Grassmere earthquake. This is consistent with the lack of damage observed following the earthquake. However, it incorrectly estimated liquefaction triggering for the remaining $50 \%$ of the profiles. Furthermore, simplified methods overestimated the extent of liquefaction triggering and consequent settlements for the shaking induced by the 2013 Cook Strait earthquake. Additional research is required to investigate nuances of the application of the simplified liquefaction procedures to the various reclamations at CentrePort. 

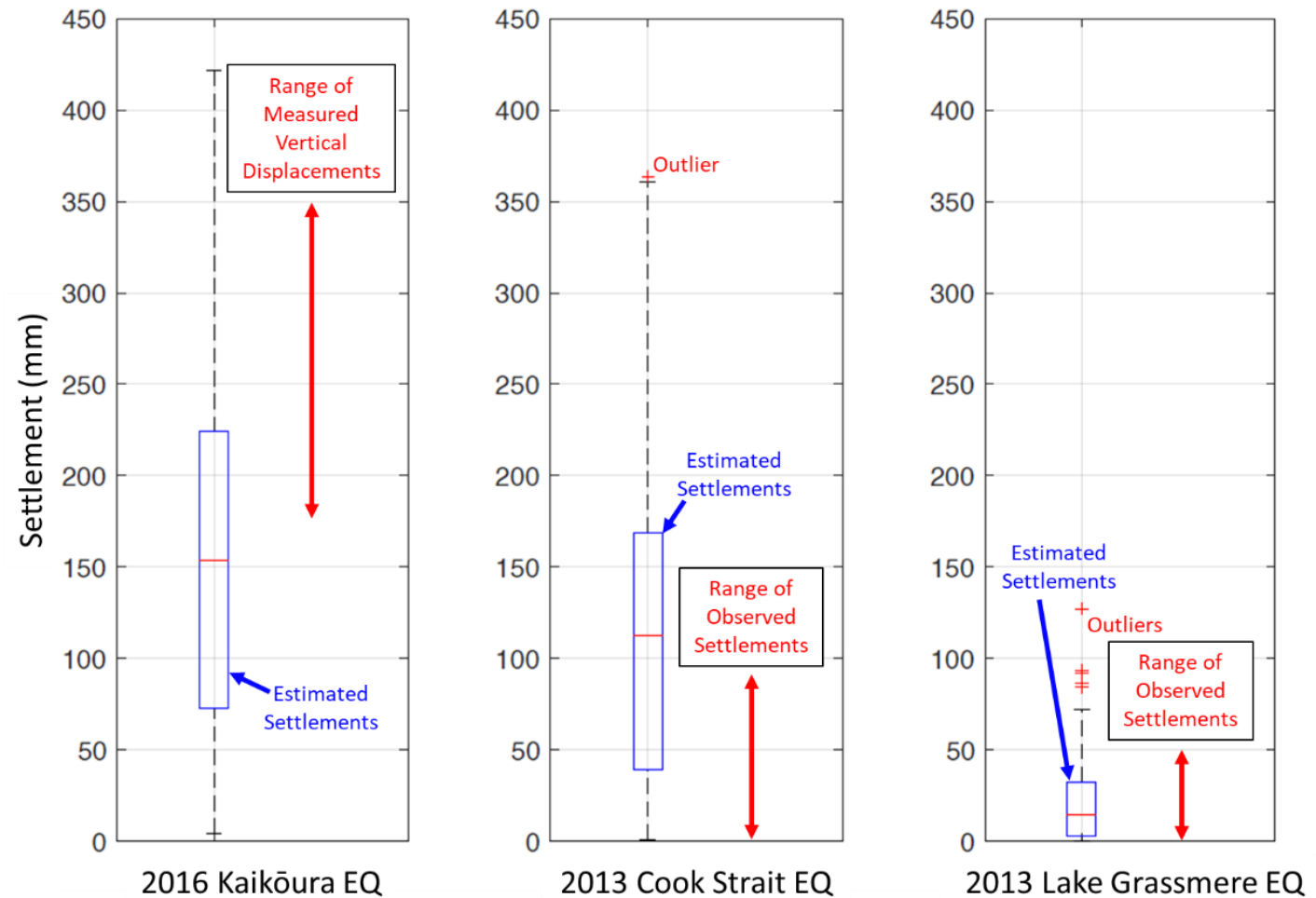

Figure 11: Box and whisker plot (modified from [19]) showing the range of estimated vertical settlements across all 121 CPTs for the 2016 Kaikōura, 2013 Cook Strait, and 2013 Lake Grassmere earthquakes. Also shown are the associated range of measured vertical settlements for the 2016 Kaikoura earthquake based on aerial surveys [6], and the associated range of estimated vertical settlements for the 2013 earthquake events based on hand measurements during post-earthquake damage assessment of CentrePort [5].

\section{ACKNOWLEDGMENTS}

This is an updated and extended version of a paper presented at the Eleventh Pacific Conference on Earthquake Engineering (PCEE) at Auckland in April 2019 [19].

Special thanks are given to Tiffany Palmer and the CentrePort Ltd. team for allowing access for multiple site visits and facilitating subsurface investigations. The authors also thank the support and research collaboration from WSP Opus, particularly Aimee Rhodes and Campbell Keepa, for providing critical input in the analysis. The authors also wish to acknowledge the exceptional site investigations performed and the cost-sharing of the MacMillan Drilling Group, especially Iain Haycock, and Tonkin \& Taylor, especially Stuart Palmer, Emilia Stocks, Richard Cole, Mike Jacka, and Sjoerd van Ballegooy, for their assistance during this study. Hugh Cowan's assistance in gaining port access is greatly appreciated. The use of aerial survey data from CARDNO is gratefully acknowledged.

The NZ team reconnaissance effort was principally supported by EQC Capability Grant at the University of Canterbury, and MBIE support provided for the 2016 Kaikōura Earthquake Reconnaissance. The US GEER team contributors were supported by the National Science Foundation (NSF) through the Engineering for Natural Hazards program under Grants CMMI-1266418 and CMMI-1724866. CPT exploration efforts were funded through the Natural Hazards Research Platform (NHRP) grant "Kaikōura Earthquake response - geotechnical characterisation of CentrePort reclamations" provided by MBIE (NZ) and NSF Grant CMMI-1724866. Any opinions, findings, and conclusions or recommendations expressed in this material are those of the authors and do not necessarily reflect the views of the NSF. This work takes advantage of data collected in a NSF-sponsored GEER reconnaissance (see: www.geerassociation.org). This project was (partially) supported by QuakeCoRE, a New Zealand Tertiary Education Commission-funded Centre. This is QuakeCoRE publication number 0480 .

\section{REFERENCES}

1 Semmens SB (2010). “An Engineering Geological Investigation of the Seismic Subsoil Classes in the Central Wellington Commercial Area". $\mathrm{PhD}$ Dissertation, University of Canterbury, Christchurch, New Zealand.

2 Dhakal R, Cubrinovski M, Bray JD and de la Torre C (2019). "Site characterization for liquefaction assessment of gravelly reclamations at CentrePort, Wellington". Proceedings of Seventh International Conference on Earthquake Geotechnical Engineering, Rome, Italy, June 17-20, 2019.

3 Cubrinovski M, Bray JD, de la Torre C, Olsen M, Bradley BA, Chiaro G, Stocks E and Wotherspoon L (2017). "Liquefaction Effects and Associated Damages Observed at the Wellington CentrePort from the 2016 Kaikōura Earthquake". Bulletin of New Zealand Society for Earthquake Engineering, 50(2): 152-173.

4 Hamling IJ, Hreinsdottir S, Clark K, Elliot J, Liang C, Fielding E, Litchfield N, Villamor P, Wallace L and Wright TJ (2017). "Complex multifault rupture during the 2016 Mw7.8 Kaikōura earthquake, New Zealand”. Science, 356.

5 Tonkin \& Taylor Ltd. (2014). "Earthquake events dated 21 July and 16 August 2013". Ref No. 85726.0.

6 Cubrinovski M, Bray JD, de la Torre C, Olsen M, Bradley BA, Chiaro G, Stocks E, Wotherspoon L and Krall T (2018a). "Liquefaction-Induced Damage and CPT Characterization of the Reclamation at CentrePort Wellington". Bulletin of the Seismological Society of America, 108(3B): 1695-1708. 
7 Bradley BA, Wotherspoon LM, Kaiser AE, Cox BR and Jeong S (2018). "Influence of Site Effects on Observed Ground Motions in the Wellington Region from the $M_{w} 7.8$ Kaikōura, New Zealand Earthquake". Bulletin of the Seismological Society of America, 108(3B): 1722-1735.

8 Vantassel J, Cox B, Wotherspoon L and Stolte A (2018). "Deep shearwave velocity profiling and fundamental site period measurements at CentrePort, Wellington and implications for locate site amplification". Bulletin of the Seismological Society of America, 108(3).

9 Tonkin \& Taylor Ltd. (2006). "Harbour Quays Development Factual Geotechnical Report". Ref No. 83725.004.

10 Tonkin \& Taylor Ltd. (2012). "Thorndon Container Wharf Seismic Assessment Geotechnical Factual Report". Ref No. 85369.001.

11 Bray JD, Cubrinovski M, Zupan J and Taylor M (2014). "CPT-Based Liquefaction Assessments in Christchurch, New Zealand". Proceedings of CPT'14: Third International Symposium on Cone Penetration Testing, Las Vegas, NV, May 13-14.

12 Robertson P (1990). "Interpretation of cone penetration tests - a unified approach". Canadian Geotechnical Journal, 46(11): 1337-1355.

13 Cubrinovski M (2019). "Some important considerations in the engineering assessment of soil liquefaction". 2019 NZGS Geomechanics Lecture, Proceedings of $13^{\text {th }}$ Australia New Zealand Conference on Geomechanics, Perth, Australia, April 1-3, 2019

14 Dhakal R, Cubrinovski M, Bray JD and de la Torre C (2019). "Site Characterisation and Liquefaction Assessment for the Reclaimed Soils in CentrePort, Wellington". Proceedings of $13^{\text {th }}$ Australia New Zealand Conference on Geomechanics, Perth, Australia, April 1-3, 2019.

15 Tonkin \& Taylor Ltd. (2017). "Pavement damage factual report". Ref. 1001154.203.
16 Boulanger RW and Idriss IM (2014). "CPT and SPT Based Liquefaction Triggering Procedures". Report No. UCD/CGM-14/01, Center for Geotechnical Modelling, Department of Civil and Environmental Engineering, University of California, Davis, USA.

17 Zhang G, Robertson PK and Brachman RWI (2002). "Estimating liquefaction-induced ground settlements from CPT for level ground". Canadian Geotechnical Journal, 39: $1168-1180$.

18 Cubrinovski M, Rhodes A, Ntritsos N and Van Ballegooy S (2019). "System response of liquefiable deposits". Soil Dynamics and Earthquake Engineering, 124: 212-229.

19 Dhakal R, Cubrinovski M, Bray JD and de la Torre C (2019). "Liquefaction assessment of reclaimed gravelly soils at CentrePort, Wellington". Proceedings of $11^{\text {th }}$ Pacific Conference on Earthquake Engineering, Auckland, New Zealand, April 4-6, 2019.

20 Van Ballegooy S, Malan P, Lacrosse V, Jacka ME, Cubrinovski M, Bray JD, O'Rourke TDO, Crawford SA and Cowan H (2014). "Assessment of liquefaction-induced land damage for residential Christchurch". Earthquake Spectra, 30(1): 31-55.

21 Iwasaki T, Tokida $\mathrm{K}$ and Tatsuoka $\mathrm{F}$ (1981). "Soil Liquefaction Potential Evaluation with Use of the Simplified Procedure". Proceedings of First International Conference on Recent Advances in Geotechnical Earthquake Engineering \& Soil Dynamics, Washington DC, USA.

22 Sibson R (1981). "Interpolating Multivariate Data" in A Brief Description of Natural Neighbor Interpolation. John Wiley \& Sons, New York, 21-36.

23 Rhodes A, Keepa C, Cubrinovski M and Krall T (2019). "Liquefaction evaluation of gravelly reclamation fill at CentrePort, Wellington". Proceedings of Seventh International Conference on Earthquake Geotechnical Engineering, Rome, Italy, June 17-20, 2019. 